\title{
Prescribing and Computers
}

\section{Standards for computer issued prescriptions}

\author{
GENERAL MEDICAL SERVICES COMMITTEE/ROYAL COLLEGE OF GENERAL \\ PRACTITIONERS JOINT COMPUTING POLICY GROUP
}

More and more prescriptions in general practice are being issued on computers, and so the General Medical Services Committee/Royal College of General Practitioners joint computing policy group considered that the time had come to put forward standards for such prescriptions. Recognised standards for prescriptions are already published in the British National Formulary, and the same standards should be followed for prescriptions issued on computers. Some of the following standards are essential, but some are only desirable.

(1) The computer should print out the patient's surname, one forename, other initials, and address. The computer could also print out the patient's title. The age of patients under 12 should be printed in the box available. A facility should exist to enable the doctor to print out the age of every patient if desired.

(2) Except in Scotland the doctor's name should be printed at the bottom of the form. This will be the name of the doctor responsible for the prescription and he will normally sign it. The doctor's surgery address, reference number, and responsible family practitioner committee (health board in Scotland) are also required. It should be possible to print the surgery telephone number in the same place on the form. In Scotland the doctor's name does not appear printed on the form.

(3) When prescriptions are to be signed by trainee assistants, assistant locums, or deputising doctors the name of the doctor printed at the bottom of the form will still be that of the responsible principal. As this name will differ from the signature, however, there might be difficulties for the pharmacist when checking the validity of the prescription. Therefore it is suggested that in this case the name of the signing doctor could be printed in the signature box and the issuing doctor would then sign over it.

(4) Drug names should normally come from a dictionary held in the machine memory. This will provide a check on the correct spelling and ensure that the name is written out in full. It may be

Joint Computing Policy Group Secretariat, BMA House, Tavistock Square, London WC1H 9JP that the system allows the user to pick out a drug from the dictionary by code or abbreviation, but these codes should not appear on the form. Whether the drug is identified by generic or proprietary name is the responsibility of the prescriber. Computers can be made to recognise both forms and print out only the preferred choice-for example, it could receive the name SEPTRIN but print out CoTRIMOXAzOLE. If drugs are prescribed that do not occur in the dictionary separate checking mechanisms are required. The user should be warned that no validation has been carried out, and the whole prescription should be entered in the lexicon.

(5) The dictionary should contain information on the normal doses, formulations, and pack sizes (where relevant) for all its items. This information may be used to produce both standard predetermined prescriptions for frequently used preparations and to check the validity of an individual prescription as it is entered.

(6) Information may be entered or stored in abbreviated form or Latin shorthand, but it is inadvisable for this to be printed on the form. Printers-particularly those at the cheaper end of the range-produce text that often fails to distinguish clearly between letters. Thus OM may look like ON. To avoid confusion the unit strength should be in numbers, the dose should be in words, and the quantity should be in numbers and in brackets.

(7) Abbreviations in the description of the strength of medication should follow the specific recommendations of the British National Formulary as follows:

(a) For solids, quantities of 1 gram or more should be written as $1 \mathrm{~g}$, etc. Quantities of less than 1 gram should be written in milligrams, for example $500 \mathrm{mg}$ not $0.5 \mathrm{~g}$. Similar quantities of less than $1 \mathrm{mg}$ should be written in micrograms-for example, 100 micrograms, not $0 \cdot 1$ grams. Micrograms and nanograms may be abbreviated to $\mathrm{mcg}$ and $\mathrm{ng}$ respectively.

(b) When decimals are unavoidable a zero should be written in front of the decimal point if there is no other figure-for example, $0.5 \mathrm{ml} \mathrm{not} .5 \mathrm{ml}$.

(c) The term "millilitre" $(\mathrm{ml})$ is used in medicine and pharmacy, and cubic centimetre, $\mathrm{cc}$, or $\mathrm{cm}^{3}$ should not be used.

(d) For liquid medicines doses should preferably be stated in terms of $5 \mathrm{ml}$ spoonfuls for children and $10 \mathrm{ml}$ quantities for adults. 
The volume of liquid preparation prescribed should normally be 50 , $100,150,200,300$, or $500 \mathrm{ml}$ or the appropriate pack size of the manufacturer.

(e) Total amounts of solids prescribed should normally be selected from the range $15,25,30,50,100,200,300$, and $500 \mathrm{~g}$ or the appropriate pack size of the manufacturer.

(8) There should be checks to ensure that all the information required to dispense an individual drug is filled in. Instructions such as "as directed" should be avoided. The instruction "when required" is acceptable only when it is desirable for the patient to vary the dose according to progress and response. In such cases it is desirable to state the maximum recommended daily dose. The computer can check that this was done.

(9) Thought should be given to the layout of the information displayed on the form. Headings that appear at the top of the form for information printed below are confusing. A clearly written prescription should not need headings such as strength, form, unit, etc. If such information is relevant to an item it should be included within that item. Abolishing abbreviations should reduce the need for such headings. Numbers and codes used in the system for organising and retrieving data must never appear on the form.

The drug name should be printed out in full and not abbreviated.

Sufficient space should be given to each item. It is too difficult to read items that have been packed onto one line. A spacer line should be inserted before each prescription.

The quantity prescribed should be clearly separated from the dose and delineated by brackets, for example. If the above recommendations are followed the quantity of tablets prescribed will be the only undefined number on the form, thus reinforcing its meaning.

The prescriber must have the facility to prescribe duration of treatment as well as quantity, and if this facility is used the dose must be specified.

The number of items per form is limited only by the ability of the printer to produce clear and well demarcated instructions.

(10) The use of a drug dictionary allows warnings and advice about the drug to be printed automatically. This is an extremely valuable facility, but when printed such information should not interfere with the clarity of the prescription itself. Any warnings or advice should be in line with the recommendation in the British National Formulary.

(11) A mechanism should be incorporated to obliterate any unused space on the form. For repeat prescriptions a series of nonspecific characters such as asterisks can be printed on the remaining space. The extra noise that this produces makes this technique unacceptable in the consulting room and the use of words after the last item on the form may be sufficient-for example, "no more items on this prescription." If there is no such provision it will be the responsibility of the issuing doctor to obliterate the remaining space on the form manually.

(12) To minimise the risk of forgery it is suggested that the computer should print the number of items to be dispensed at a convenient position on the form. This should be in a separate place to the box already provided for use by the pharmacist, which serves a different function.

(13) Handwritten alterations should be used only in exceptional circumstances as they may make the prescription illegible and increase the risk of unauthorised amendments. It is preferable to issue a new prescription from the machine. In this way only can a record of the prescription as it is issued be held in the system. When handwritten alterations are made they must be in the doctor's handwriting and countersigned by him.

(14) Prescriptions for controlled drugs cannot be written by a printer. When a record of such a prescription needs to be kept in the machine, however, a device should exist to allow this but prevent the inadvertent or malicious printing of the item.

(15) The strip of paper on the side of the FP10 (Comp) may be used for various purposes at the discretion of the doctor. Care should be taken, however, to avoid putting any confidential information on that piece of paper as it may be read by people other than the patient. It may be advisable for the patient's name to appear at the top of the piece of paper, but it is suggested that this should be preceded by the words "Confidential" to protect the issuing doctor.

(16) In rural dispensing practices requests for a prescription or the medicines dispensed will normally be entered in one surgery but may be required to be delivered to another surgery or location. If possible there should be up to 10 choices to indicate where the prescription or the medicine prescribed should be delivered.

(17) It is obvious from examples of computer issued prescriptions available that abbreviations and unspecified descriptions are being used-presumably to save memory in the system. These should not be used as they may cause confusion.

(18) Where appropriate these guidelines will also cover the issuing of private prescriptions.

In the future computer records are likely to be legally valid records for subsequent proceedings. In large and complex systems it may be that the computer will hold the only record of what has been prescribed. It should therefore contain the FULL details of what has been prescribed within the patient record file, suitably annotated with the date.

This paper was drafted on behalf of the Joint Computing Policy Group by Dr G M Hayes.

\section{YEARS AGO}

The intolerable uncertainty which attends parliamentary business, as at present conducted, was never more strikingly shown than on Tuesday evening, when the militia-surgeons fondly hoped to have had the opportunity of laying their grievances before the House of Commons. All the arrangements had been carefully planned. Sir E. Wilmot was to lead the attack, and was to have been seconded by Dr. Farquharson from the other side; others had promised to speak, and a large number of members had expressed their intention of supporting the motion. Dr. MacCormack had been hard at work for days past, sending out circulars and enlisting sympathy, and the Chairman of the Parliamentary Bills Committee had placed the influence of his powerful organisation at the command of those who were about to advocate the good cause. All seemed to promise well for an animated debate, a good division, and a possible consent on the part of the Government to the very moderate demand about to be made for a committee of inquiry into the hardships so harshly imposed upon a body of hard working and deserving public servants. But, alas for "the best laid schemes of mice and men," Mr. Warton had unhappily obtained the first place on the notice-paper, and the temptation was irresistible to pay out the "champion blocker" for the persistent way in which he obstructed the legislative efforts of private members; and, in addition to this plausible reason for a count, the honourable member for Bridport had already exhausted the patience of the house by talking at inordinate length earlier in the afternoon on a railwayBill; so that, when he rose to discuss the subject of Wednesday sittings, a veritable stampede at once began, which nearly emptied the benches. The confusion had scarcely subsided, when the Speaker's attention was directed to the fact that forty members were not present; and, after the proper interval had elapsed, and heads had been duly counted, the quorum was found to be short of its proper number by thirteen. Disappointing as was this result of so much hard work and careful preparation, it is hoped that another opportunity may be found of bringing the subject before the House; and an informal consultation was held in the lobby between Sir E. Wilmot, Dr. Farquharson, and Dr. Lyons (who had hurried back from the Medical Council to take part in the debate), as to the best mode of procedure. It was agreed that a further effort should be made to bring the question forward after Whitsuntide, on going into Committee of Supply. With this view, several of those who are specially interested will ballot for a place; and, if this fail, recourse can then be had to the last expedient of all, which is to raise a discussion on the pension-vote in the Army Estimates. We therefore confidently hope that the good seed sown during the last and present sessions will yet bear good.fruit. (British Medical Journal 1885;i:1065.) 